Байкальский государственный университет, г. Иркутск, Российская Федерация

В. А. Оглоблин

Иркутский государственный университета путей сообщения, 2. Иркутск, Российская Федерация

\title{
СОВЕРШЕНСТВОВАНИЕ МЕТОДОВ МЕНЕДЖМЕНТА ПРОМЫШЛЕННЫХ ПРЕДПРИЯТИЙ В РАЗРЕЗЕ ПОДХОДОВ К УПРАВЛЕНИЮ
}

\begin{abstract}
АннотАция. Рассмотрены существующие подходы к управлению промышленными предприятиями и применяемые группы методов менеджмента. Приведены основные характеристики функционального, процессного, системного и ситуационного, подходов к управлению. Проанализированы применяемые на практике группы методов менеджмента. Проведено сопоставление применяемых методов менеджмента по различным подходам к управлению. Предложена группировка подходов к управлению промышленным предприятием на основе выделения функционального и процессного подхода в организующую категорию системного и ситуационного подходов к управлению. Обосновано построение «Матрицы» подходов к управлению промышленным предприятием для определения применяемых методов менеджмента. Разработан механизм применения комплексной функции менеджмента для оценки проводимых изменений в системе управления промышленным предприятием.

кЛючЕВыЕ словА. Управление; менеджмент; методы менеджмента; функциональный подход к управлению; процессный подход к управлению; системный подход к управлению; ситуационный подход к управлению; комплексная функция менеджмента.

ИНФОРМАЦИЯ О СТАТЬЕ. ата поступления 31 января 2018 г.; дата принятия к печати 19 марта 2018 г.; дата онлайн-размещения 09 апреля 2018 г.
\end{abstract}

L. G. Sokolova Baikal State University, Irkutsk, Russian Federation

V. A. Ogloblin

State Railway Engineering University, Irkutsk, Russian Federation

\section{IMPROVING MANAGEMENT METHODS FOR INDUSTRIAL ENTERPRISES IN TERMS OF MANAGEMENT APPROACHES}

\begin{abstract}
The article considers the existing approaches to management of industrial enterprises and applied groups of management methods. It gives the main characteristics of functional, process, systematic and situational approaches to management, analyzes the practical groups of management methods, makes a comparison of the applied management methods with different approaches to management. The article offers the grouping of approaches to the management of the industrial enterprise on the basis of separation of the functional and process approaches into the organizing category of systemic and situational approaches to management; it substantiates the construction of the "Matrix" of approaches to management of an industrial enterprise in order to identify the applied management methods; it develops the mechanism of applying an integrated management function in assessing the ongoing changes in the management system of the industrial enterprise.
\end{abstract}

\section{Baikal Research Journal}


KEYWORDS. Management; management methods; functional approach to management; process approach to management; system approach to management; situational approach to management; complex function of management.

ARTICLE INFO. Received January 31, 2018; accepted March 19, 2018; available online April 09, 2018.

В научной литературе рассматриваются несколько подходов к управлению промышленными предприятиями: функциональный, процессный, системный и ситуационный. Научную школу управления, административную школу и школу человеческих отношений, по нашему мнению, можно рассматривать как функциональный подход к управлению [1]. Процессный подход состоит в использовании сквозных бизнес-процессов организации, «пересекая» границы функциональных подразделений, при этом, разрушаются барьеры между подразделениями, связывается воедино деятельность структурных подразделений и в конечном итоге, результат представляется в виде ценности для стейкхолдеров и потребителей [2]. Основная идея системного подхода к управлению состоит в рассмотрении объектов исследования как систем и их проектирование. Каждая система является сложной совокупностью элементов, которая состоит из взаимосвязанных между собой подсистем более низкого порядка. Подобная структура должна обладать единством с внешней средой и способствовать достижению конечных целей и задач деятельности предприятия [3]. Ситуационный подход к управлению рассматривает систему факторов, воздействующих на предприятие, формирующих определенную ситуацию. Эта ситуация определяет условия, в которых может обеспечиваться устойчивое развитие предприятия [4].

В рамках подходов к управлению используются различные методы менеджмента, которые определяют эффективность системы управления промышленными предприятиями и сказываются на достижении стратегических целей организации. Однако, практика показывает, что используются прежде всего исторически сложившиеся на предприятии методы менеджмента. В редких случаях, менеджмент организации начинает применять элементы процессного управления, наряду с функциональным подходом к управлению.

Анализируя применяемые в процессе управления методы менеджмента можно условно подразделить их на три группы: организационно-административные, экономические и социально-психологические [5].

Применение организационно-административных методов менеджмента предусматривает организационное воздействие, распорядительное воздействие и расстановку кадров. Экономические методы менеджмента основаны на нормировании. Все функциональные процессы и показатели результатов деятельности должны быть рассчитаны на основе научно обоснованных норм, а осуществление оценки деятельности и контроля предполагает, соответствие всем нормам и требованиям. На этой основе формируется система стимулирования, побуждающая к эффективному и производительному труду (в виде увеличения заработной платы, премирования, выплат и вознаграждений). Социально-психологические методы сводятся, прежде всего, к формированию коллектива. Коллектив - это сложившаяся, устойчивая социальная группа людей, для которой характерна общность цели, совместный труд, наличие органов самоуправления, сознательная дисциплина, взаимное уважение и понимание друг друга. Формирование производственного коллектива - результат целенаправленной деятельности людей, сознательного приложения их усилий ${ }^{1}$. Сформированный коллектив должен быть способен эффективно выполнить поставленные перед ним цели.

${ }^{1}$ URL: https://www.intuit.ru/studies/courses/3640/882/info.

\section{Baikal Research Journal}

электронный научный журнал Байкальского государственного университета 
Сравнительная характеристика применяемых на практике групп методов менеджмента позволяет определить их основные характерные черты и условия применения в различных подходах к управлению, существующих на промышленном предприятии (табл. 1) [5].

Адлинистративные, эконолические

Таблица 1. и социально-психологические методы менеджлента

\begin{tabular}{|l|l|l|l|}
\hline & $\begin{array}{c}\text { Административные } \\
\text { (принуждение) }\end{array}$ & $\begin{array}{c}\text { Экономические } \\
\text { (побуждение } \\
\text { и принуждение) }\end{array}$ & $\begin{array}{l}\text { Социально-психологические } \\
\text { (побуждение) }\end{array}$ \\
\hline Основа применения & Угроза наказания & $\begin{array}{l}\text { Возможность } \\
\text { увеличить доход }\end{array}$ & $\begin{array}{l}\text { Достижение психологиче- } \\
\text { ского комфорта }\end{array}$ \\
\hline $\begin{array}{l}\text { Подходы } \\
\text { к реализации }\end{array}$ & $\begin{array}{l}\text { Адаптивные } \\
\text { к ситуации }\end{array}$ & Адаптивные к личности \\
\hline $\begin{array}{l}\text { Требования } \\
\text { к субъекту }\end{array}$ & $\begin{array}{l}\text { Исполнительность, } \\
\text { организованность }\end{array}$ & Профессионализм & $\begin{array}{l}\text { Профессионализм, умение } \\
\text { работать в команде, иници- } \\
\text { ативность }\end{array}$ \\
\hline
\end{tabular}

Проведем сопоставительную характеристику применяемых на промышленных предприятиях подходов к управлению и методов менеджмента. Сравнительные характеристики подходов к управлению и организационно административных методов (табл. 2) выявили диаметрально противоположные действия менеджмента при смене подходов к управлению. При переходе от функционального управления к процессному управлению вертикальные связи менеджмента должны быть заменены на горизонтальные. Формулируемые цели деятельности в системном подходе, с учетом деятельности подсистем организации, при ситуационном управлении заменяются на направления возможного изменения ситуации.

Такие кардинальные изменения в действиях менеджмента промышленного предприятия, от смены подходов к управлению, практически делают невозможным внедрение современных методик деятельности, поскольку это связано с обучением всего персонала одновременно и резкими изменениями в организационной структуре предприятия.

Таблица 2

Сравнительная характеристика применения организационно адлинистративных методов менеджлента по различныл подходал к управлению

\begin{tabular}{|c|c|c|c|}
\hline $\begin{array}{c}\text { Функциональный } \\
\text { подход }\end{array}$ & Процессный подход & $\begin{array}{c}\text { Системный } \\
\text { подход }\end{array}$ & Ситуационный подход \\
\hline $\begin{array}{l}\text { Разделение труда } \\
\text { по видам деятель- } \\
\text { ности и функци- } \\
\text { ям, вертикально } \\
\text { структурирован- } \\
\text { ная иерархическая } \\
\text { система управле- } \\
\text { ния, выполнение } \\
\text { сотрудником од- } \\
\text { ной или несколь- } \\
\text { ких подобных } \\
\text { простых операций } \\
\text { с учетом четкой } \\
\text { регламентации } \\
\text { труда [6] }\end{array}$ & $\begin{array}{l}\text { Ответственность за } \\
\text { качество процес- } \\
\text { са, горизонталь- } \\
\text { ная структура с } \\
\text { идентификацией } \\
\text { ответственности } \\
\text { за каждый биз- } \\
\text { нес-процесс, вы- } \\
\text { полнение разноо- } \\
\text { бразных функций, } \\
\text { требующих широ- } \\
\text { кого круга знаний } \\
\text { и творческого } \\
\text { подхода к решению } \\
\text { проблем [6] }\end{array}$ & $\begin{array}{l}\text { Определяются } \\
\text { и формули- } \\
\text { руются цели } \\
\text { функциониро- } \\
\text { вания системы, } \\
\text { определяются } \\
\text { требования, } \\
\text { которым долж- } \\
\text { на удовлетво- } \\
\text { рять система, } \\
\text { формируются } \\
\text { подсистемы и } \\
\text { организация } \\
\text { их в единую } \\
\text { систему [7] }\end{array}$ & $\begin{array}{l}\text { Организация должна обеспечить } \\
\text { объективную оценку общей си- } \\
\text { туации, определить направления } \\
\text { возможного изменения ситуации, } \\
\text { установить цели устойчивого раз- } \\
\text { вития предприятия, обеспечить } \\
\text { деятельность предприятия по ре- } \\
\text { ализации этих целей, установить } \\
\text { факторы, которые могут оказы- } \\
\text { вать на ситуацию значительное } \\
\text { влияние, но при этом обладают } \\
\text { управляемостью со стороны ме- } \\
\text { неджмента организации обеспе- } \\
\text { чить формирование более благо- } \\
\text { приятной ситуации [4] }\end{array}$ \\
\hline
\end{tabular}

\section{Baikal Research Journal}


Рассматривая применения экономических методов менеджмента по различным подходам к управлению (табл. 3), то здесь также отмечаются значительные различия в формировании мотивационной системы. Если при функциональном подход к управлению не предусматривается персональная оценка деятельности работника по экономическим показателям, то при ситуационном подходе к управлению вознаграждение работника полностью зависит от персональной оценки его деятельности.

Таблица 3

Сравнительная характеристика применения экономических методов менеджмента по различным подходам к управлению

\begin{tabular}{|c|c|c|c|}
\hline $\begin{array}{c}\text { Функциональный } \\
\text { подход }\end{array}$ & $\begin{array}{c}\text { Процессный } \\
\text { подход }\end{array}$ & Системный подход & Ситуационный подход \\
\hline $\begin{array}{l}\text { Заинтересован- } \\
\text { ность в резуль- } \\
\text { тате выполнения } \\
\text { должностных } \\
\text { функций, или } \\
\text { подразделения [6] }\end{array}$ & \begin{tabular}{|l|} 
Заинтере- \\
сованность \\
в качестве \\
производ- \\
ственного и \\
трудового \\
процессов [6]
\end{tabular} & $\begin{array}{l}\text { Мотивация персонала на выполне- } \\
\text { ние целей и задач производствен- } \\
\text { ной инфраструктуры машино- } \\
\text { строительного предприятия путем } \\
\text { системы премирования, вручения } \\
\text { благодарственных писем, разме- } \\
\text { щения на доске почета и других } \\
\text { форм материального и нематери- } \\
\text { ального стимулирования [3] }\end{array}$ & $\begin{array}{l}\text { Современная система } \\
\text { бонусов для успешных } \\
\text { сотрудников, которая } \\
\text { предполагает } \\
\text { не только экономи- } \\
\text { ческие, но также и } \\
\text { социальные «мотива- } \\
\text { торы» [8] }\end{array}$ \\
\hline
\end{tabular}

Рассматривая методические подходы к применения социально-психологических методов менеджмента по подходам к управлению промышленным предприятием следует отметить их возрастающую роль от функционального к ситуационному подходу (табл. 4).

Если предположить, что в исторической перспективе промышленное предприятие, начиная с функционального подхода к управлению, в процессе своего роста переходят к применению процессного подхода, совершенствуя свою деятельность при помощи системного подхода, затем применяют ситуационный подход, то в таком случае не должно возникать неразрешимых проблем в применении усовершенствованных методов менеджмента. Однако практика деятельности промышленных предприятий не позволяют утверждать, что функциональный подход полностью замещается процессным, а процессный системным. Речь, скорее всего, идет о диффузии элементов методов менеджмента в различные подходы к управлению промышленным предприятием.

Таблица 4

Сравнительная характеристика применения социально-психологических методов менеджмента по различным подходам к управлению

\begin{tabular}{|c|c|c|c|}
\hline $\begin{array}{c}\text { Функци- } \\
\text { ональный } \\
\text { подход }\end{array}$ & $\begin{array}{c}\text { Процессный } \\
\text { подход }\end{array}$ & Системный подход & Ситуационный подход \\
\hline $\begin{array}{l}\text { Заинтересо- } \\
\text { ванность в } \\
\text { результате } \\
\text { выполнения } \\
\text { функций [6] }\end{array}$ & $\begin{array}{l}\text { Максималь- } \\
\text { ное удов- } \\
\text { летворение } \\
\text { внутренних } \\
\text { потребителей. } \\
\text { Поощрение } \\
\text { участия в } \\
\text { процесса } \\
\text { обучения и } \\
\text { повышения } \\
\text { компетентно- } \\
\text { сти в области } \\
\text { качества [6] }\end{array}$ & $\begin{array}{l}\text { Осуществление коллегиаль- } \\
\text { ного управления, где ответ- } \\
\text { ственность за принятое реше- } \\
\text { ние будет ложиться на всех и } \\
\text { общий результат совпадает с } \\
\text { личными целями каждого. В } \\
\text { системном подходе нет места } \\
\text { конкуренции. Можно только } \\
\text { использовать соревнования } \\
\text { между подразделениями и } \\
\text { работниками как один способ } \\
\text { повышения опыта и навыков } \\
\text { команды [9] }\end{array}$ & $\begin{array}{l}\text { Ведущую роль в реализации } \\
\text { целей ситуационного управле- } \\
\text { ния играет организационная } \\
\text { культура. Рациональная куль- } \\
\text { тура позволяет организации } \\
\text { адекватно действовать в самых } \\
\text { разных, в том числе неблаго- } \\
\text { приятных ситуациях. [4] } \\
\text { Потребности подчиненных (са- } \\
\text { мореализация, возможность } \\
\text { творчески проявить себя, раз- } \\
\text { витие, возможность высказы- } \\
\text { вать свои идеи руководству) [8] }\end{array}$ \\
\hline
\end{tabular}

\section{Baikal Research Journal}


В современной научной литературе появились работы о целесообразности применения гибридного подхода к управлению, например, в рамках функционального подхода предлагают использование элементов процессного подхода [10], в рамках системного используется процессный подход $[9 ; 11 ; 12]$.

Исследовав применяемые подходы к управлению промышленными предприятиями, соответствующие им методы менеджмента, современные теоретические направления исследований, считаем целесообразным выделение функционального и процессного подхода в организующую категорию системного и ситуационного подходов к управлению (табл. 5).

Таблица 5

Предлагаемая группировка подходов к управлению промышленным предприятием

\begin{tabular}{|c|c|c|}
\hline & Системный подход & Ситуационный подход \\
\hline $\begin{array}{l}\text { Функциональный } \\
\text { подход }\end{array}$ & $\begin{array}{l}\text { Деятельность в условия и вид } \\
\text { работы которой зависят от цели, } \\
\text { выполняется с помощью функций } \\
\text { Преобладание и экономических } \\
\text { групп методов управления }\end{array}$ & $\begin{array}{l}\text { Деятельность по созданию благо- } \\
\text { приятной ситуации выполняется с } \\
\text { помощью функций } \\
\text { Преобладание экономических и } \\
\text { социально-психологических групп } \\
\text { методов управления }\end{array}$ \\
\hline $\begin{array}{l}\text { Процессный } \\
\text { подход }\end{array}$ & $\begin{array}{l}\text { Деятельность в рамках организа- } \\
\text { ционной структуры, условия и вид } \\
\text { работы которой зависят от цели, } \\
\text { выполняется с помощью процессов } \\
\text { Преобладание экономических и } \\
\text { административных групп методов } \\
\text { управления }\end{array}$ & $\begin{array}{l}\text { Деятельность по созданию благо- } \\
\text { приятной ситуации выполняется с } \\
\text { помощью процессов } \\
\text { Преобладание социально-психоло- } \\
\text { гических и экономических групп } \\
\text { методов управления }\end{array}$ \\
\hline
\end{tabular}

В каждом из подходов к управлению присутствует разная степень осуществления групп методов управления, что и определяет, по нашему мнению, доминирующий подход к управлению, который сказывается на результативности и эффективности методов менеджмента промышленных предприятий.

Мы считаем, что системный и ситуационный подходы к управлению отличаются от функционального и процессного прежде всего тем, что у последних не описано критериев, по которым можно было бы судить об успешности системы управления организации и, наоборот, у функционального и процессного подходов есть инструмент при помощи которого осуществляется деятельность, а вот у системного и ситуационного подходов к управлению их нет (явно не указаны). Именно поэтому мы объединяем подходы к управлению функциональный - процессный, системный - ситуационный и предлагаем рассматривать методы менеджмента в системе координат подходов к управлению (рис. 1).

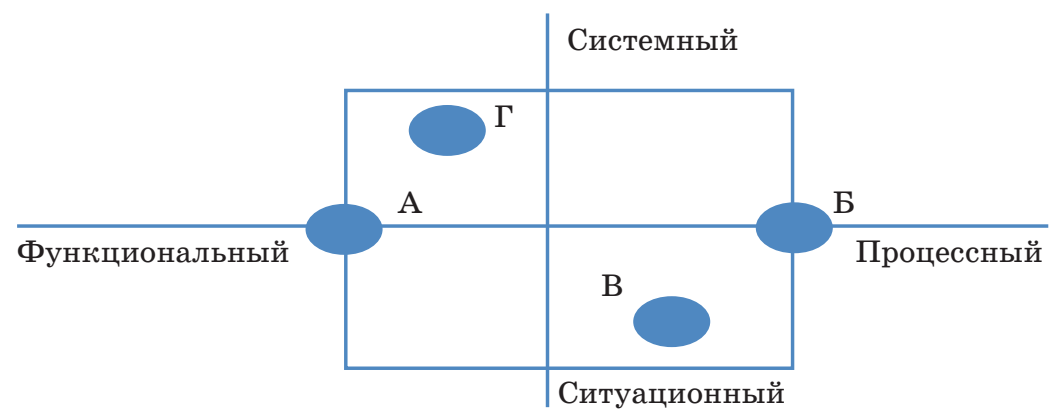

Рис. 1. «Матрища» подходов к управлению

\section{Baikal Research Journal}


Построив «Матрицу» подходов к управлению промышленным предприятием можно определить применяемый на предприятии подход к управлению и возможность внедрения усовершенствованных методов менеджмента.

Например, точка A - показывает, что в организации преобладает функциональный подход к управлению, но ни системный, не ситуационный подход не используется совсем. Точка Б - показывает, что в организации преобладает процессный подход к управлению, но ни системный, не ситуационный подход не используется совсем. Примеров для использования только системного, или ситуационного подхода к управлению на этом графике нет. Однако, точка В, показывает преобладание ситуационного и процессного подхода, а точка $\Gamma$ - системного и функционального. На базе этих подходов к управлению можно определить такой гибридный подход, который бы имел максимум преимуществ и минимум недостатков.

Данное представление не дает оснований к выводу, какой из подходов к управлению является самым эффективным и результативным для некоего предприятия, однако можно утверждать, что каждый из них обладает своими преимуществами и недостатками, которые мы можем осознанно использовать для применения методов менеджмента на практике.

Современное состояние экономического развития требует от работников управленческого труда быстрой перестройки методов менеджмента, которые часто могут не согласовываться с подходами к управлению на предприятии, с формированием новой структуры и т.п.

В этих условиях возрастают требования к квалификации менеджера, умении его в рамках действующей организационной структуры и созданной ситуации, достигать поставленных целей выполняя отдельные функции или комбинируя их в процесс, реализуемый с помощью выбранных им методов управления. Для оценки квалифицированных действий работника умственного труда по выбору методов управления менеджмента предлагается использовать комплексные функций менеджмента. При ее формировании за основу берется функциональный подход к управлению, и проектируется таким образом [13], чтобы можно было оценить внедрение новых методов менеджмента в деятельности работника. Результат выполняемых комплексных функций менеджмента, связанных общей стратегической целью предприятия можно оценить при помощи использования разработанной методики [14].

Данный подход [15] позволяет объединить функциональный (комплексная функция строится из элементарных функций), процессный (комплексная функция в некотором смысле является процессом) и системный (комплексную функцию оценивают в контексте теории систем) подходы к управлению, избежать недостатков присущих данным подходам и воспользоваться их преимуществами.

\section{Список использованной литературы}

1. Воронкова И. Е. Наука управления: основные школы / И. Е. Воронкова // Экономическая среда. - 2015. - № 4 (14). - С. 93-97.

2. Лисичкина Ю. С. Процессный подход в управлении организацией / Ю. С. Лисичкина, Ю. К. Сычев // Управленческие науки в современном мире. - 2017. - № 1. C. $134-137$.

3. Мезенцев Д. С. Реализация системного подхода к управлению производственной инфраструктурой машиностроительного предприятия / Д. С. Мезенцев // Актуальные вопросы современной науки. - 2016. - № 1 (6). - С. 39-48.

4. Куликова О. И. Ситуационный подход к управлению устойчивым развитием предприятия / О. И. Куликова // Многоуровневое общественное воспроизводство: вопросы: теории и практики. - 2015. - № 8 (24). - С. 150-161.

\section{Baikal Research Journal}

электронный научный журнал Байкальского государственного университета 
5. Основы менеджмента / М. В. Цыпленкова. - М. : Рос. Академия Естествознания, 2013. - $130 \mathrm{c.}$

6. Кладов А. В. Использование функционального и процессного подходов к управлению производственными процессами / А. В. Кладов // Вестник Воронеж. гос. техн. унта. - 2011. - Т. 7, № 1. - С. 145-148.

7. Иноземцев В. П. Принципы системного подхода в управлении предприятием / В. П. Иноземцев // Новая наука: опыт, традиции, инновации. - 2016. — № 3-1 (71). C. $86-90$.

8. Ситуационный подход в управлении организациями / М. М. Михайлова [и др.] // Экономика и управление в XXI веке: тенденции развития. - 2014. — № 14. - С. 116-121.

9. Фейзуллаев М. А. Модернизация системного подхода к управлению предприятием / M. А. Фейзуллаев // Теория и практика общественного развития. - 2017. — № 4. C. 47-51.

10. Калачева Е. А. Функциональный и процессный подходы к управлению / Е. А. Калачева // Материалы Междунар. науч.-техн. конф., Москва, 1-5 дек. 2015 г. - М., 2015. C. $143-146$.

11. Гумеров М. Ф. Управление бизнес-процессами на основе системного подхода / М. Ф. Гумеров // Управленческие науки в современном мире. - 2017. — № 1. — С. 138-142.

12. Цвигун И. В. Городское самоуправление: тенденции организационного развития / И. В. Цвигун, М. В. Вихорева. - Иркутск : Изд-во БГУЭП, 2009. - 112 с.

13. Оглоблин В. А. Алгоритм формирования комплексной функции кадрового менеджмента [Электронный ресурс] / В. А. Оглоблин // Управление экономическими системами. — 2017. — № 5 (99). — Режим доступа: http://uecs.ru/index.php?option=com_flexicon tent\&view $=$ items\&id $=4401$.

14. Соколова Л. Г. Оценка результатов кадрового менеджмента в условиях функционирования системы управления персоналом / Л. Г. Соколова, В. А. Оглоблин // Baikal Research Journal. - 2016. - T. 7, № 3. - Режим доступа: http://brj-bguep.ru/reader/ article.aspx?id=20775. - DOI : 10.17150/2411-6262.2016.7(3).18.

15. Оглоблин В. А. Организационный подход к формированию комплексных функций кадрового менеджмента / В. А. Оглоблин // Научный диалог: экономика и менеджмент : материалы VI междунар. науч.-практ. конф., 8 мая 2017 г. - СПб., 2017. - С. 28-31.

\section{References}

1. Voronkova I. E. Management science: basic schools. Ekonomicheskaya sreda = Economic Environment, 2015, no. 4 (14), pp. 93-97. (In Russian).

2. Lisichkina Yu. S., Sychev Ju. K. Process approach in organizational management. Upravlencheskie nauki $v$ sovremennom mire = Managerial sciences in the modern world, 2017, no. 1, pp. 134-137. (In Russian).

3. Mezentsev D. S. Implementation of the system approach to management of industrial infrastructure of a machine-building enterprise. Aktual'nye voprosy sovremennoi nauki = Actual Issues of Modern Science, 2016, no. 1 (6), pp. 39-48. (In Russian).

4. Kulikova O. I. Situational approach to management of sustainable enterprise development. Mnogourovnevoe obshchestvennoe vosproizvodstvo: voprosy teorii i praktiki $=$ Multilevel Public Reproduction: Issues of Theory and Practice, 2015, - no. 8 (24), pp. 150-161. (In Russian).

5. Tsyplenkova M. V., Moiseenko I. V., Guremina N. V., Bondar Ju. A. Osnovy menedzhmenta [Basics of management]. Moscow, Russian Academy of Natural History Publ., 2013. $130 \mathrm{p}$.

6. Kladov A. V. Use of functional and process approaches to management of production processes. Vestnik Voronezhskogo gosudarstvennogo tekhnicheskogo universiteta = Proceedings of Voronezh University, 2011, vol. 7, no. 1, pp. 145-148. (In Russian).

7. Inozemtsev V. P. Principles of system approach in enterprise managemen. Novaya nauka: opyt, traditsii, innovatsii = New Science: Experience, Traditions, Innovations, 2016, no. 3-1 (71), pp. 86-90. (In Russian).

8. Mikhailova M. M., Zheksenbaeva A., Klepandina S. A., Ushnitskii O. A., Fillipov F. S. Situational approach to organizational management. Ekonomika i upravlenie $v$ XXI veke: tendentsii razvitiya = Economics and Management in the $21^{\text {st }}$ Century: Development Trends, 2014, no. 14, pp. 116-121. (In Russian).

\section{Baikal Research Journal}


9. Feizullaev M. A. Modernization of system approach to enterprise management. Teoriya $i$ praktika obshchestvennogo razvitiya = Theory and practice of social development, 2017, no. 4, pp. 47-51. (In Russian).

10. Kalacheva E. A. Functional and process management approaches. Materialy Mezhdunarodnoi nauchno-tekhnicheskoi konferentsii, Moskva, 1-5 dekabrya 2015 g. [Materials of International Research Conference, Moscow, December, 2015]. Moscow, 2015, pp. 143-146. (In Russian).

11. Gumerov M. F. Management of business processes on the basis of systematic approach. Upravlencheskie nauki $v$ sovremennom mire = Managerial sciences in the modern world, 2017, no. 1, pp. 138-142. (In Russian).

12. Tsvigun I. V., Vikhoreva M. V. Gorodskoe samoupravlenie: tendentsii organizatsionnogo razvitiya [City government: directions of organizational development]. Irkutsk, Baikal State University of Economics and Law Publ., 2009. 112 p.

13. Ogloblin V. A. Formation algorithm of complex function of personnel management. Upravlenie ekonomicheskimi sistemami $=$ Management of economic systems, 2017, no. 5 (99). Available at: http://uecs.ru/index.php?option=com_flexicontent\&view=items\&id=4401. (In Russian).

14. Sokolova L. G., Ogloblin V. A. Assessing results of personnel management in terms of functioning of personnel management system. Baikal Research Journal, 2016, vol. 7, no. 3. DOI : 10.17150/2411-6262.2016.7(3).18. Available at: http://brj-bguep.ru/reader/article. aspx?id=20775. (In Russian).

15. Ogloblin V. A. Organizational approach to formation of complex functions of personnel management. Nauchnyi dialog: ekonomika i menedzhment. Materialy 6 mezhdunarodnoi nauchno-prakticheskoi konferentsii, Sankt-Peterburg, maya 2017 g. [Scientific dialogue: economics and management. Materials of International Scientific Conference, Saint-Petersburg, May, 2017]. Saint-Petersburg, 2017. pp. 28-31. (In Russian).

\section{Информация об авторах}

Соколова Лариса Георгиевна - доктор экономических наук, профессор, кафедра государственного и муниципального управления, Байкальский государственный университет, 664003, г. Иркутск, ул. Ленина, 11, e-mail: sokolova-lg@yandex.ru.

Оглоблин Владилир Александрович - старший преподаватель, кафедра менеджмента, Иркутский государственный университет путей сообщения, 664074, г. Иркутск, ул. Чернышевского, 15, e-mail: ogloblinva@mail.ru.

\section{Authors}

Larisa G. Sokolova - Doctor habil. in Economics, Professor, Chair of Public Administration, Baikal State University, 11 Lenin St., 664003, Irkutsk, e-mail: sokolova-lg@yandex.ru.

Vladimir A. Ogloblin - Senior Lecturer, Chair of Management, Irkutsk State Railway Engineering University, 15 Chernyshevsky St., 664074, Irkutsk, e-mail: ogloblinva@mail.ru.

\section{Для цитирования}

Соколова Л. Г. Совершенствование методов менеджмента промышленных предприятий в разрезе подходов к управлению / Л. Г. Соколова, В. А. Оглоблин // Baikal Research Journal. - 2018. — T. 9, № 1. - DOI : 10.17150/2411-6262.2018.9(1).8.

\section{For Citation}

Sokolova L. G., Ogloblin V. A. Improving Management Methods for Industrial Enterprises in Terms of Management Approaches. Baikal Research Journal, 2018, vol. 9, no. 1. DOI: 10.17150/2411-6262.2018.9(1).8. (In Russian).

\section{Baikal Research Journal}

